\title{
VIRTUAL INDECENT ASSAULT: TIME FOR THE CRIMINAL LAW TO ENTER THE REALM OF VIRTUAL REALITY
}

\author{
Joshua Hansen*
}

\begin{abstract}
Virtual reality has the potential to provide a new medium of communication that will allow community, business and recreation to extend into the virtual realm. As with any emerging technology, the law must decide how to respond. When technology throws into question what the law considers to be real, we are starting from a relatively clean slate. The purpose of this article is to consider the extent to which the criminal law must engage with virtual reality. This issue is approached through the case study of virtual indecent assault. After considering the offence of indecent assault in s 135 of the Crimes Act 1961 and the effects of virtual actions, this article argues that the potential for harm justifies the intervention of the criminal law into virtual worlds. In light of this conclusion, this article also aims to outline a set of principles that can shape the criminal law's response. A principled approach can establish a stable foundation from which to tackle the diverse and often unknown challenges posed by an ever changing technology. These principles are applied in the evaluation of the different methods of criminalisation that would be available in the context of virtual indecent assault.
\end{abstract}

\section{INTRODUCTION}

In 2016, a woman named Jordan Belamire was the victim of a virtual sexual assault. ${ }^{1}$ Her viral blog post describing the incident triggered the legal and virtual reality communities to consider the potential of virtual acts to cause real harm. Stories such as Belamire's give us a glimpse into the issues that must be dealt with as we experience the dawn of virtual technology. The particular issues that capture my interest are those that emerge from virtual reality's unique feature: the complete immersion of the user. Virtual reality's aim is to trick the user's mind into thinking that their virtual experiences are real. Studies have shown that subjects who are slapped in virtual reality respond with skin

* $\quad$ Originally submitted for the LLB (Honours) Degree, Faculty of Law, Victoria University of Wellington, 2018. Revised for submission to the Victoria University of Wellington Law Review. I would like to express thanks to my supervisor Professor Yvette Tinsley, for her invaluable advice and support.

1 Jordan Belamire "My First Virtual Reality Groping" (6 October 2016) Medium <www.medium.com>. 
conductance and heart rate levels as if they were actually slapped. ${ }^{2}$ If something feels real and our body reacts to it as if it is real, at what point will the law have to intervene?

In this article, I will build a case for the criminalisation of certain virtual acts. I will do so by considering whether the law should hold an actor criminally liable for committing an indecent assault in a virtual world. This requires consideration of the real world offence of indecent assault under $\mathrm{s}$ 135 of the Crimes Act. I will argue that the criminal law must engage with virtual reality on the basis that virtual indecent assault can cause real harm.

I will then outline principles that should underpin any action taken by the criminal law in an effort to effectively prevent and punish this harm. These principles must be capable of managing the complex and intricate issues that will be faced in criminalising virtual indecent assault. They also apply to virtual reality generally and should be used to build a foundation from which the next steps can be taken. I will apply these principles to evaluate which possible criminalisation method would be most appropriate for virtual indecent assault.

Although none of the methods suggested are perfect, my hope is to provide a starting point for the type of analysis that will need to be undertaken. I do not propose that the criminal law is the only vehicle to prevent and punish unacceptable virtual actions, rather that it must be considered a viable option. I accept that this discussion raises some questions that cannot be answered within the scope of this article. Ultimately, the most important starting point is the acknowledgement that real harm can result from virtual acts. This fact should form the backbone of any future action.

\section{UNDERSTANDING VIRTUAL REALITY \\ A A Working Definition of Virtual Reality}

The term "cross reality" refers to multiple forms of technology that manipulate a user's reality. The different paradigms of mixed reality sit on what has been labelled a reality-virtuality continuum. ${ }^{3}$ This continuum is a scale. At one end is technology that helps users interact with the real world. At the other is technology where users interact with an entirely virtual world. I am concerned with the virtual end of the spectrum. Virtual reality allows the user to embody an avatar and then interact with their virtual environment. A working definition of virtual reality that is appropriate in this context is that developed by Frederick Brooks: ${ }^{4}$

2 Mark A Lemley and Eugene Volokh "Law, Virtual Reality, and Augmented Reality" (2018) 166 U Pa L Rev 1051 at 1065

3 Frank Steinicke Being Really Virtual: Immersive Natives and the Future of Virtual Reality (Springer International Publishing, Basel, 2016) at 5.

4 At viii. 
Virtual Reality (VR) requires three real features: (i) real-time rendering with viewpoint changes as head moves, (ii) real space, i.e., either concrete or abstract 3D virtual environments, and (iii) real interaction, i.e., possible direct manipulation of virtual objects.

Brooks' definition is not completely adequate for the purposes of this article. I am concerned with virtual environments that are accessible to multiple users simultaneously. Users must also have a strong degree of individual autonomy in deciding how they will interact with the environment and other users. These two features will supplement Brooks' definition.

The form of virtual technology I will consider does not include haptic technology. ${ }^{5}$ The use of haptic technology provides an extreme form of virtual immersion where an avatar's sense of touch is felt directly by the user who is wearing a full or partial body suit. I intend to demonstrate that actual harm can result from virtual acts without the use of haptic technology. One should, however, keep in mind that with haptics on the horizon, the intensity of immersion is only going to increase.

\section{$B$ The Significance of the Cross Reality Industry}

The virtual reality industry continues to develop and grow at a rapid pace. New Zealand's cross reality sector is predicted to achieve over NZD 320,000,000 in annual revenue and double the number of people it employs by 2020. ${ }^{6}$ In 2014, Facebook bought Oculus for USD 2,300,000,000. Oculus develop virtual reality headsets primarily for gaming. This illustrated significant confidence in the future of virtual reality technology. Another significant event was the 2014 release of the "Google Cardboard", an affordable and accessible form of virtual reality named after what the product is primarily made of. The cheap box, when combined with a phone and 360 degree videos, allows for a passive virtual reality experience. ${ }^{7} 2016$, however, is regarded as the breakthrough year for the cross reality sector with the release of four major virtual reality hardware platforms. ${ }^{8}$ A 2016 report from Greenlight Insights stated that growth in the virtual reality sector would be "very modest" through 2018, in an "inflexion zone" until 2021, and will grow significantly after that point, becoming a USD $36,000,000,000$ industry by $2026 .{ }^{9}$ The turning point is envisaged to be the production of wireless computing headsets. ${ }^{10}$ There is no doubt that the gaming industry is the driving force behind the

5 Oxford English Dictionary "haptic, adj"<www.oed.com>.

6 New Zealand VR/AR Association "Virtual Gets Real: The Explosion of Cross Reality in New Zealand" (Report One, September 2017) at 91.

7 Alexandra Lange "The Magic of a Cardboard Box" The New York Times (online ed, New York, 7 June 2018).

8 Lemley and Volokh, above n 2, at 1055.

9 Greenlight Insights 2016 Virtual Reality: Consumer Adoption Report (November 2016), as referred to in Daniel Terdiman "VR Will Be A \$38 Billion Industry by 2026: Report" Fast Company (online ed, United States of America, 11 February 2016).

10 Terdiman, above n 9. 
development of virtual reality. The USD 90,000,000,000 industry will expose a large number people to the unique sensation of entering a virtual realm. ${ }^{11}$ The future of virtual reality does, however, extend beyond gaming. It has the potential to act as an extension of everyday life. Shopping, job interviews, business meetings, schooling, medical training and even psychotherapy could all occur in virtual environments. ${ }^{12}$

\section{Criminalising Virtual Acts}

Complex legal issues are arising as a consequence of the growth in virtual reality. The questions raised echo those that emerged with the development of the Internet. Virtual reality has the potential to engage all areas of the law: issues of intellectual property, hacking and privacy will all need to be managed if people are going to invest part of their lives in a virtual environment. These issues have already come to light in programmes that allow free action in virtual worlds such as the game "Second Life". Nevertheless, I am particularly interested in the issues that emerge from the unique element of complete immersion. Immersion is what distinguishes virtual reality from any other communication technology. The level of immersion will only become more comprehensive as the technology develops. As the boundaries between reality and virtuality are blurred, a user can develop psychological responses to an attack on their virtual body as if it were their own. This issue is pertinent as a user's freedom in virtual environments allows - and at times encourages - harmful behaviour. Anonymity, lack of consequence and gaming culture have already led to numerous sexual harassment incidents in virtual worlds. This is why I am concerned with virtual acts that would constitute indecent assault if the act were committed in the real world. The surrounding discussion and underlying questions are, however, also applicable to other offences that could be committed in virtual worlds.

The criminal law's intervention into virtual environments is a challenging concept. What happened in the virtual world would no longer stay in the virtual world. Any regulation that one imposes on virtual environments requires a policy decision as to what role immersive virtual environments should hold in society. The intervention of the criminal law is only one of many options that may be adopted in regulating virtual actions. Virtual reality developers should also take responsibility for punishing offenders. Offending users could be given warnings, face punishment within the virtual environment or be banned from the environment entirely. Some platforms have already introduced a personal bubble, where if a user interferes with another user's personal space, they disappear from the victim's sight. ${ }^{13}$ Computer code is a form of rules that can be employed to manage these issues. ${ }^{14}$ There are,

11 Dean Takahashi "Worldwide game industry hits $\$ 91$ billion in revenues in 2016, with mobile the clear leader" (21 December 2016) Venture Beat <www.venturebeat.com>.

12 Lemley and Volokh, above n 2, at 1055.

13 Katherine Cross "Sexual assault enters virtual reality" (10 November 2016) The Conversation $<$ www.theconversation.com>.

14 Lemley and Volokh, above n 2, at 1075. 
however, situations where the harm caused will be serious enough to require the criminal law to intervene.

\section{A CASE FOR CRIMINALISATION: THE HARM OF VIRTUAL INDECENT ASSAULT}

\section{A The Issue}

In 2019, virtual reality for the consumer is still in its early stages and not yet established in the mainstream. Virtual environments are accessed through headsets and headphones. One's sense of immersion is limited by graphics and the need to attach the headset to an external computing device. The time is ripe to consider the role the criminal law will play in its development. Legislators should have a grasp of the technology in its early stages. This will allow them to signal their intention that virtual worlds will not exist completely outside of the law. Developers can then work constructively with the expectations of society in mind. The law can help prevent behaviour like virtual indecent assault from being normalised at an early stage where our understanding of the technology and users' attitudes towards it are malleable. I will explain why virtual indecent assault is a useful entry point into this issue of criminalisation with reference to s 135 of the Crimes Act. I then outline the theoretical framework of criminalisation that should be applied in this context before using that framework to demonstrate why the criminal law should intervene.

\section{B Virtual Indecent Assault}

In 2016, Jordan Belamire shared her experience of being virtually groped while playing a virtual multi-user game called QuiVr. ${ }^{15}$ In between a sequence of shooting incoming enemies with a bow and arrow, the avatar of the stranger she was playing with, BigBro442, turned to her and started rubbing her virtual crotch and groin. Belamire later wrote that the incident felt "real" and "violating". ${ }^{16}$ The realness of the incident from the perspective of Belamire is what generates the relevance of virtual indecent assault. It is useful for the purposes of clarity to break down the act that occurred in Belamire's story. An avatar controlled by a human groped another avatar controlled by another human within an immersive virtual environment. This is the type of act that is considered in this case study. If this event happened in a street of New Zealand, BigBro442 would be charged under s 135 of the Crimes Act for indecent assault. I will argue that BigBro442 should be held criminally liable under a similar offence despite the fact that the act occurred in a virtual world.

\section{Section 135: Indecent Assault}

Before considering the possibility of criminalising virtual indecent assault, it is helpful to understand the nature of the offence in the real world. Section 135 of the Crimes Act states that

\footnotetext{
15 Belamire, above $\mathrm{n} 1$.
}

16 Belamire, above $\mathrm{n} 1$. 
"[e]very one is liable to imprisonment for a term not exceeding 7 years who indecently assaults another person." Under s 2(1B) of the Act, one person does an indecent act on another person whether they do an indecent act with or on the other person; or induces or permits the other person to do an indecent act with or on them. The word "indecent" is taken as the ordinary word in the English language. ${ }^{17}$ The Oxford English Dictionary defines indecent as "[u]nbecoming; highly unsuitable or inappropriate; contrary to the fitness of things; in extremely bad taste; unseemly". ${ }^{18}$ In $R v$ Nazif, it was stated that "indecent" must be interpreted according to the current standards of what is indecent, thereby reflecting the attitudes of the community. ${ }^{19}$

It should be emphasised that indecent assault can occur through a wide range of forms of physical contact. Assault is the intentional act of applying or attempting to apply force to the person of another. ${ }^{20}$ The lightest touching can be an assault as a matter of law, but it must be done intentionally. ${ }^{21}$ Physical contact is not a necessary element for a charge of indecent assault. An attempt or threat of applying force is sufficient. ${ }^{22}$ In $T S v R$, the defendant exposed himself to the complainant at her front porch while holding the door so she couldn't close it and asked her to have sex with him. ${ }^{23}$ This was sufficient for the Court of Appeal to classify it as a threat that would have been carried out had the complainant not resisted by closing the door. ${ }^{24}$ It is clear that emotional and psychological effects arising from the threat are the central harms which the offence responds to. This type of harm remains squarely in focus throughout the following discussion.

\section{Principles of Criminalisation}

In any discussion of criminalisation, a starting point from a liberal perspective is Mill's assertion "[t]hat the only purpose for which power can be rightfully exercised over any member of a civilized community, against his will, is to prevent harm to others." ${ }^{25}$ Under Mill's principle, the law's ability

$17 R v$ Nazif [1987] 2 NZLR 122 (CA) at 127.

18 Oxford English Dictionary "indecent, adj" < www.oed.com>.

$19 R v$ Nazif, above n 17, at 127.

20 Crimes Act 1961, s 2.

$21 R v$ Aylwin [2007] NZCA 458 at [35].

22 Crimes Act, s 2.

$23 T S \vee R$ [2012] NZCA 419 at [5].

24 At [7].

25 JS Mill 'On Liberty' and other Writings (Stefan Collini (ed), 8th ed, Cambridge University Press, Cambridge, 2012) at 22. 
to criminalise behaviour is constrained. Feinberg approaches harm from a more open-ended perspective when he states: ${ }^{26}$

It is always a good reason in support of penal legislation that it would probably be effective in preventing (eliminating, reducing) harm to persons other than the actor (the one prohibited from acting) and there is probably no other means that is equally effective at no greater cost to other values.

Both statements recognise that the criminal law should not intervene unless truly needed to prevent harm. Conversely, Lord Devlin would argue that our starting point should be wrongfulness. In his book The Enforcement of Morals, Devlin writes: ${ }^{27}$

... it is not possible to set theoretical limits to the power of the State to legislate against immorality ... or

to define inflexibly areas of morality into which the law is in no circumstances allowed to enter.

I will therefore approach the question of criminalisation of virtual indecent assault through a discussion of both harm and wrongfulness. Simester and von Hirsch support this approach, noting that "an exclusive reliance on harm is apt to mislead. It diverts attention from the more general inquiry when we should prohibit wrongful conduct."28

\section{E Identifying Real Acts}

Unique to a criminalisation analysis in the context of virtual reality is the underlying need to establish that certain virtual acts are real. There is a concept called the "magic circle" that categorises virtual actions. ${ }^{29}$ Purely virtual acts that are only significant within virtual worlds lie within the magic circle and cannot be considered real. These acts are said to have intra-virtual effects. ${ }^{30}$ Acts outside that circle have extra-virtual effects. Extra-virtual effects are those that stem from a virtual action but have consequences that carry over into the real world. Only virtual acts which have extra-virtual effects can qualify as real acts. ${ }^{31}$ Although this distinction is useful, the category of intra-virtual acts is limited. There is strong evidence provided below that most virtual acts carried out in immersive environments will have extra-virtual effects on the user. Once virtual acts are considered to be real as

26 Joel Feinberg Harm to Others: The Moral Limits of the Criminal Law (Oxford University Press, New York, 1984) vol 1 at 26.

27 Lord Devlin The Enforcement of Morals (Oxford University Press, Oxford, 1987) at 12-13, as cited in AP Simester and Andreas von Hirsch Crimes, Harms and Wrongs: On the Principles of Criminalisation (Hart Publishing, Oxford, 2011) at 21.

28 Simester and von Hirsch, above n 27, at 21.

29 Joshua AT Fairfield "The Magic Circle" (2009) 11 Vand J Ent \& Tech L 823 at 824

30 Johnny Hartz Soraker "Virtual Worlds and Their Challenge to Philosophy: Understanding the 'Intravirtual' and the 'Extravirtual"' (2012) 43 Metaphilosophy 499 at 505.

31 At 505 
a result of the consequences that follow, criminalisation is then dependent on the nature of those consequences.

\section{F Criminalisation on the Basis of Harm}

In light of s 135, emotional and psychological trauma should be seen as the harmful consequence that determines the gravity of indecent assault. This recognition immediately diminishes the role of physical force in the offence, narrowing the void between real and virtual indecent assault. The conclusion that virtual indecent assault causes real harm then bridges this void. This connection justifies the interference of the criminal law.

\section{What happens in the virtual world does not stay in the virtual world}

In Belamire's blog, she describes the intense sensation of standing on a cliff's edge as her first experience of virtual reality. The same could be said for the virtual groping that followed: "[t]he public virtual chasing and groping happened a full week ago and I'm still thinking about it."32 Belamire is not alone in being shocked by the sensation of virtual reality. Multiple studies have come to the conclusion that, cognitively speaking, there is little to no difference between virtual and real events as far as the nervous system is concerned. This is why virtual realities are possible in the first place. ${ }^{33}$ One common virtual reality experiment asks the subject who is immersed to stand at the edge of a deep pit. They are instructed to lean over the edge. In order to enhance the illusion the user stands on a piece of wood three centimetres above the ground. Despite the knowledge that they are not about to fall into a deep pit, the subjects nevertheless show increased signs of stress through increases in heart rate and skin conductance. ${ }^{34}$

Physiological responses to virtual actions are mirrored by psychological responses. A study that involved a virtual variation of the famous Milgram Shock experiment, found that humans tend to respond realistically at physiological and behavioural levels in interaction with virtual characters notwithstanding their certainty that they are not real. ${ }^{35}$ In this experiment, the subject who is immersed in virtual reality knows that they are only administering an electric shock to a virtual person. Nevertheless, the physiological responses resemble that of subjects who know they are administering

32 Belamire, above n 1.

33 Roland Wojak "Virtual Reality: The Moral Status of Virtual Actions" (Master's Thesis, Colorado State University, 2012) at 33.

34 Michael Madary and Thomas K Metzinger "Real Virtuality: A Code of Ethical Conduct. Recommendations for Good Scientific Practice and the Consumers of VR-Technology" (2016) 3(3) Frontiers in Robotics and AI 1 at 6.

35 Mel Slater and others "A Virtual Reprise of the Stanley Milgram Obedience Experiments" (2006) 1(1) PLoS ONE 1 at 2 . 
an electric shock to a real person. ${ }^{36}$ These studies demonstrate that we cannot discount the real physiological and psychological effects actions in virtual reality can have on a user.

\section{The special harm of indecent assault}

An act of indecent assault in a virtual environment has the potential to cause the user extreme extra-virtual harm. This is explained through consideration of the harm of indecent assault in the real world. The psychological harm of sexual offences derives from the compromise to one's physical integrity. This compromise is inextricably linked to one's emotional and psychological state and, therefore, one's personality and sense of self. ${ }^{37}$ This link between the physical and the deeply personal establishes the special wrong that is committed when a sexual offence occurs. ${ }^{38}$ Sexual violation erodes sexual autonomy and sexual choice. Sexuality is not a physical thing, but a part of one's personality that must be voluntarily expressed. ${ }^{39}$ Indecent assault removes one's ability to control what is deeply personal. ${ }^{40}$ It is a violation of one's sense of agency. A study on rape conducted in 1983 concluded that: ${ }^{41}$

... rape is an experience which shakes the foundations of the lives of the victims. For many its effect is a

long term one, impairing their capacity for personal relationships, alternating their behaviour and values and generating fear.

Indecent assault, although not as severe a violation as rape, can also shake the foundations of one's life.

In summary, the harm of indecent assault derives from the compromise of bodily integrity and manifests in the effect on one's individual sense of agency. The link between bodily integrity and agency is exactly what is manipulated during a period of virtual immersion. Herein lies the vulnerability of a victim of virtual indecent assault. The link between the two central concepts of embodiment and agency should be examined to demonstrate the potential of this vulnerability.

The effectiveness of virtual reality hinges on the illusion of embodiment. Virtual reality takes a user's sense of self and places it within the virtual body. By tracking the movements of the user and

36 At 1.

37 Mary Childs "Review Article: Sexual Autonomy and Law" (2001) 64 MLR 309 at 311.

38 Elisabeth McDonald and Yvette Tinsley "Rejecting 'one size fits all': Recommending a range of responses" in From 'Real Rape' to Real Justice: Prosecuting Rape in New Zealand (Victoria University Press, Wellington, 2011) 377 at 418.

39 At 418.

40 At 418

41 Warren Young Rape Study Volume 1: A Discussion of Law and Practice (Department of Justice, 1983) at 34, as cited in McDonald and Tinsley, above n 38, at 418, n 146. 
rendering the virtual body to copy those movements, ${ }^{42}$ the body becomes the user's own. ${ }^{43}$ The operating elements of a virtual user can be divided into three parts. The user's actual body controls a virtual body, whilst the user's sense of self is transported between the two. The actual body still plays an active role as its movements trigger the movements of a virtual being. Virtual reality establishes a relationship between a person and their avatar as a sort of mind-body dualism, where the body is not a corporeal body, but a virtual one. ${ }^{44}$ The necessary corollary is that what happens to one's virtual body could have a similar effect on one's self as if the same thing had happened to their physical body.

The user's sense of agency is manipulated to create this illusion of embodiment. The strength of the connection between one's mind and virtual body was emphasised in a study initiated by Nick Yee and Jeremey Bailenson who developed a theory labelled the Proteus Effect. ${ }^{45}$ They found that the appearance of the avatar the user embodied altered their behaviour directly in line with their preconceived beliefs of how someone of that appearance would act. ${ }^{46}$ Another study found that subjects who embodied older versions of themselves over a long period of time showed a tendency to allocate more money to their retirement fund after leaving the virtual environment. ${ }^{47}$ This indicates that one's sense of self in a virtual world manipulates one's sense of self post-immersion in the real world. Users who are immersed and have built second lives with their virtual bodies may have such a strong sense of agency that it is indistinguishable from their real bodies. Michael Madary noted that depersonalisation disorder is relevant here because virtual reality's underlying purpose is to generate realness. ${ }^{48}$ Even though users know their virtual body is not real, the illusionary feelings can be overpowering as one's agency becomes vulnerable to manipulation. ${ }^{49}$ There is therefore potential for one's sense of agency and bodily integrity to be just as vulnerable in virtual environments as in reality. Although more research is needed, this analysis shows that real harm can occur from virtual indecent assault.

It could be argued that a user's ability to remove a headset justifies treating virtual acts of indecent assault less seriously, but this is not a strong counterargument. This solution infringes a user's freedom within a virtual environment. More importantly, one's ability to escape a situation does not change the

42 Wojak, above n 33, at 12.

43 At 14 .

44 At 26.

45 Nick Yee and Jeremy Bailenson "The Proteus Effect: The Effect of Transformed Self-Representation on Behavior" (2007) 33 Human Communication Research 271 at 271.

46 At 274.

47 Madary and Metzinger, above $n$ 34, at 7.

48 At 14.

49 At 1. 
culpability of the offender. In reality, a victim of indecent assault may have the ability to escape physically yet this may not occur out of fear or hesitancy. The same difficulties apply in the virtual world. Removing a headset when immersed in virtual environments may not be instinctual for users due to the illusion of embodiment and a distorted sense of agency. Furthermore, even if a victim does escape, emotional harm may still result from the experience.

\section{G Criminalisation on the Basis of Wrongfulness}

Virtual environments are sometimes perceived as places to which morality does not extend, a place for people to purge their desires. This perspective feeds the argument that an analysis of the morality of virtual actions is not necessary as it runs against the purpose of a virtual world. This is, however, based on a narrow understanding of the potential of virtual environments and the harm that can be caused within them. Indeed, certain virtual environments that involve combat games for example, may allow the user to intentionally assault another avatar. Users will consent to those actions occurring when they enter the environment. Many environments, however, will not be designed for users to have free rein. Consent and different standards of acceptable behaviour within a virtual environment do not completely remove morality from virtual reality. The potential of real and immediate harm means the wrongfulness of virtual acts can and should be considered.

The ambiguous relationship between virtual worlds and morality have led writers to couch their analysis of wrongfulness within a harm-based approach. Roland Wojak justifies his discussion of the moral wrongfulness of actions in virtual environments through the acknowledgement of real world harm. He stresses that virtual interactions are still between real people when stating: ${ }^{50}$

... regardless of how the self is characterized, there is reason to believe that it can extend or be affected by actions that take place within virtual worlds, and as such, those actions should be objects of moral consideration.

This justification is consistent with the observations of Ashley John Craft who stated: ${ }^{51}$

... users have the same de facto duties towards each other when they interact within virtual spaces as they

do when writing in print, talking over the telephone, or meeting in person.

Based on this analysis, harm is placed at the forefront. Morality is subject to the presence of harm. This is consistent with Simester and von Hirsch's assertion that, for certain actions, the wrong derives from the harm. ${ }^{52}$

50 Wojak, above n 33, at 57.

51 Ashley John Craft "Sin in cyber-eden: understanding the metaphysics and morals of virtual worlds" (2007) 9 Ethics and Inf Technol 205 at 216, as cited in Wojak, above n 33, at 84 (emphasis added).

52 Simester and von Hirsch, above n 27, at 29. 
It is, however, arguable that the wrong of virtual indecent assault is distinct from the harm. The wrong can be derived from the decision to capitalise on the distinction between the real and virtual world. This distinction is characterised by the apparent freedom to act in a virtual world without consequence; the behaviour is morally reprehensible because although the user can do whatever they wish, they take advantage of this to indecently assault another. Freedom is therefore the necessary condition for a virtual action to be the subject of moral consideration. ${ }^{53}$ The exploitation of this freedom and the thrill users derive from immoral virtual actions is precisely how they transgress ethical boundaries. ${ }^{54}$ Simester and von Hirsch write: "[h]uman beings, instead, are moral but fallible creatures - capable of being motivated by normative appeals, but sometimes inclined to offence nevertheless." 55 It is in virtual reality where humans may forget morality and be inclined to offend in ignorance of the harm they cause. Criminalisation would signal widespread moral disapproval of this behaviour, reaffirming morality as a deterrent in virtual worlds. The concept of deterrence complements this analysis of wrongfulness. The fact that certain users act virtually in ways they would never in reality, solely because they do not feel morally bound, is further justification for legal intervention. This is necessary when one considers the potential for harm.

The wrongfulness of virtual indecent assault also derives from the harm to wider society. The undertaking of virtual indecent assault reflects an unacceptable attitude towards sexual offences and sexual integrity. Recent and much-needed societal condemnation and growing awareness of sexual offending could be eroded if we allow these virtual acts to remain unpunished. Allowing such behaviour to occur in a virtual world only enhances a societal structure under which female sexual agency is already undermined by patriarchal ideologies. ${ }^{56}$ This process would completely counteract the flow of the current progress in speaking up against sexual assault and exposing fundamental issues in society's treatment of women. Criminalisation of virtual indecent assault would prevent further distortion of attitudes towards sexual violence and set a clear standard of virtual behaviour.

\section{THE PRINCIPLES OF CRIMINALISING VIRTUAL ACTS}

It has been established that real harm can result from virtual acts. This justifies the intervention of the criminal law into virtual reality. Real action needs to be taken to respond to this real harm. The wrongfulness of certain virtual acts and the theory of deterrence support this intervention. The law will need guidance and careful management as it engages with the continuously developing and complex world of virtual technology. I will set out a set of principles that I believe should be followed

53 Wojak, above n 33, at 90 .

54 At 92 .

55 Simester and von Hirsch, above n 27, at 14.

56 John Danaher "The law and ethics of virtual sexual assault" in Woodrow Barfield and Marc Jonathan Blitz (eds) Research Handbook on the Law of Virtual and Augmented Reality (Edward Elgar Publishers, Cheltenham, 2018) 363 at 375-376. 
in the creation of any legal instrument that criminalises virtual actions such as indecent assault. These principles are constructed with the goal of facilitating the effective prevention and punishment of harmful virtual behaviour. They are directly tied to the unique difficulties the law will face when engaging with virtual indecent assault. Following the establishment of the principles, I will discuss which form of legal instrument may best facilitate the achievement of these principles in the context of virtual indecent assault. None of the options suggested are perfect. Nevertheless, they all provide possibilities that can be developed and improved upon through further research.

\section{A Principles}

\section{The law must adequately define virtual reality, leaving sufficient scope for future development and change}

Law reform is often outrun by technology as regulations address immediate issues with technology that then quickly evolve beyond the scope of the law. This has been labelled the "pacing problem". ${ }^{57}$ A carefully drafted definition of virtual reality will be necessary to ensure successful management of the technology. Drafting of legislation will require a difficult balancing act of achieving specificity in describing the type of technology the law seeks to control, whilst allowing enough flexibility to cope with technological developments. A possible starting point is the definition used in this article adapted from Brooks' work. ${ }^{58}$ Virtual reality requires five real features:

(i) real-time rendering with viewpoint changes as head moves;

(ii) real space, i.e. either concrete or abstract 3D virtual environments;

(iii) real interaction, i.e. possible direct manipulation of virtual objects;

(iv) autonomy and active decision making by the user; and

(v) multi-user access.

\section{Current case law should be used as a guide to application but kept at arm's length}

A balanced approach towards defining virtual reality must also be adopted in the adjustment of legal tests to achieve congruency with their virtual contexts. Legal tests enable the courts to determine whether the offence has occurred. The normal legal tests for indecent assault cannot, however, haphazardly be applied due to the different circumstances of virtual acts. Once again, a balance will have to be struck between specificity and flexibility. The example of virtual indecent assault highlights the type of issues that will be confronted. Indecent assault requires intentional or attempted application of force upon another's body. In a virtual reality context, this must now include virtual bodies and

57 Andrew Askland "Introduction: Why Law and Ethics Need to Keep Pace with Emerging Technologies" in Gary E Marchant, Braden R Allenby and Joseph R Herkert (eds) The Growing Gap Between Emerging Technologies and Legal-Ethical Oversight: The Pacing Problem (Springer, Dordrecht, 2011) xiii at xx.

58 Steinicke, above n 3, at 5. 
virtual force. The language used must reflect the capabilities of the virtual environment itself and therefore could not become overly specific. Any law would need to acknowledge the virtuality of the acts, whilst explaining the acts in simple and clear terms. Interestingly, it has been suggested that the word power rather than force would be more appropriate as a key concept of indecent assault in the real world. ${ }^{59}$ Power is broader than physical force and leaves room for psychological aspects to influence the law. ${ }^{60}$ This would further narrow the void between indecent assault in reality and virtual reality as the physical element is diminished. This language would certainly be more appropriate in a virtual world. This is the kind of linguistic decision that will have to be carefully considered.

A more complex element is what constitutes "indecent" in a virtual environment. This demonstrates why the current law for physical acts should be kept at arm's length. Under the current law, what is considered indecent is gauged by what a jury considers to be within current standards of indecency. ${ }^{61}$ This test faces difficulty when applied to virtual reality, particularly if there is not widespread understanding of what constitutes virtual reality or how the experience of being in an immersive environment feels. Community standards of what is decent in reality cannot easily be applied to virtuality. The differences between reality and virtuality allow for the argument that there should be a higher threshold for what constitutes an indecent act in the virtual world. Each virtual environment will have different standards of what is acceptable. This will vary depending on the environment's purpose, the demographic of the users and what they consent to when entering the environment. The social contract has the potential to be rewritten. The concept of a new social contract and the issue of what one consents to when entering a virtual world exposes a raft of questions that requires discussion beyond the scope of this article. It will be necessary to determine at what stage the law should step in if the social contract is distorted to an offensive extent. Nevertheless, at this early stage, when faced with the issue of defining "indecent" in a virtual context, a good starting point is the acknowledgement that real harm can result from virtual acts. This baseline would at least provide a safety net for the standards of indecency. From there any legal test can be developed while remaining loyal to the need to prevent harm.

\section{Any new law or regulation must be flexible, amenable and adopt technology- neutral language}

Any legal instrument that is developed to engage with virtual environments must be able to react to any developments in the technology. This goes beyond the definition of virtual reality and will depend on the form and wider content of the instrument. Technology-neutral language can be adopted throughout to prevent the law from becoming stagnant and quickly anachronistic. This language

59 Childs, above n 37, at 149.

60 At 149.

$61 R v$ Nazif, above n 18 at 127. 
focuses on the wider type of technology as a whole rather than a specific piece of technology. ${ }^{62}$ It must, however, be specific enough in order to address the issues the law faces. An example that is pertinent to virtual indecent assault is the development of haptic technology. Haptics will allow virtual experiences to be physically felt. The consequences of virtual indecent assault are severe and should be responded to even in the absence of this physical element. The law must, however, keep in mind that haptic technology is on the horizon. Any legal instrument that is created should be comprehensive and flexible in order to cope with the use of haptics.

\section{The law's intent should be clearly indicated while it waits for the appropriate time to engage}

The law must decide whether it should pre-emptively legislate on the issues that are suspected to arise. One of the benefits of this decision is that the law can then frame how the technology will develop along with users' attitudes towards it. It also provides a legal framework for developers to work within, preventing unforeseen legal barriers at a later stage. On the other hand, it may be beneficial to wait until the technology has passed what has been labelled an "impact threshold" before engaging. ${ }^{63}$ This threshold rests where society and legislators have a higher level of understanding of the technology so issues can be more specifically identified and managed. Determining when the technology has reached that threshold is difficult when it is developing at a breakneck pace. The impact threshold of virtual reality has arguably not yet arrived. It is, however, not far away. I would prioritise the need to become more aware of the role that virtual technology will play in society over immediate action. It will be important not to approach the issue so narrowly that any law becomes irrelevant after a sudden change in the technology. Waiting for the impact threshold is therefore a suitable and perhaps necessary option while further research and planning is undertaken.

\section{If the decision is made to delay the imposition of any legislation until the impact threshold, other active steps must be undertaken in the meantime.}

If legislation is not implemented in the short term, in the meantime those who develop virtual reality technology and lawmakers should maintain a list of unknowns as they emerge. ${ }^{64}$ For virtual reality, the list of what is unknown about the future of the technology is expansive and continuously evolving. These unknowns, if documented, prevent assumptions from being made and widen one's understanding of what is possible. To complement this list of unknowns, a system of categorisation

62 Lydia Bennett Moses "Sui Generis Rules" in Gary E Marchant, Braden R Allenby and Joseph R Herkert (eds) The Growing Gap Between Emerging Technologies and Legal-Ethical Oversight: The Pacing Problem (Springer, Dordrecht, 2011) 77 at 90.

63 Askland, above n 57, at xv.

64 David Rejeski "Public Policy on the Technological Frontier" in Gary E Marchant, Braden R Allenby and Joseph R Herkert (eds) The Growing Gap Between Emerging Technologies and Legal-Ethical Oversight: The Pacing Problem (Springer, Dordrecht, 2011) 47 at 53. 
of the forms of cross reality should be created. These steps would delay the implementation of the criminal law on virtual reality. Nevertheless, this may be a good strategy in building a foundation upon which the law may act.

\section{Issues of jurisdiction should not act as a barrier to criminalisation}

One of the unknowns is how the law will regulate virtual environments that are accessed from around the world. An indecent assault may be initiated by someone accessing the environment in the United States, with the victim accessing the environment from New Zealand. It is unlikely the law will be able to enforce any criminal punishment on a foreign actor or that a state will be willing to extradite that actor for such an offence. It is unclear where the law will consider the act to have taken place. Is it from where the actor or the victim is accessing the environment? Or perhaps it is where the host server of the virtual platform is located? A similar issue has arisen in the enforcement of cybercrime and online harassment. This jurisdictional problem stresses the importance of virtual reality developers regulating harmful behaviour. Enforcement through computer code does not see national boundaries as the criminal law would. Merely placing responsibility on platform owners, however, will not be sufficient to prevent the harm that can be caused. Although difficulties with jurisdiction will arise, this should not be a barrier to criminalisation. New Zealand perpetrators could be convicted of the offence under New Zealand law, deterring other users from committing such virtual acts.

\section{A strong point of communication between legislators and virtual reality developers should be established while obligations are imposed upon them}

Alongside issues of jurisdiction are issues of enforcement. These challenges can only be approached if a strong relationship between virtual reality developers and lawmaking authorities exists. This will allow for a constructive dialogue on the liability of virtual reality developers and help to establish effective regulations on the technology. Enforcement issues will require regulation of platform developers to ensure there are appropriate safeguards built into virtual environments. For example, identifying the actor in any assault would prove difficult without a built-in surveillance system. It may be necessary to force developers to secure and survey their virtual environments. This particular problem could be resolved by recording a user's virtual experiences. In this respect, once measures are put in place, it may in fact be easier to enforce the law. This in itself raises privacy issues which are outside the scope of this article.

A further issue that platform developers must actively manage is the ability of minors to enter virtual environments and not present themselves as such. The imposition of age restrictions on certain environments will be necessary along with sufficient protections to enforce those restrictions. It is widely known that children play games with R18 ratings. The consequences of this will be more severe with virtual reality games where children are directly interacting with adults. This is particularly pertinent to indecent assault. The law will have to decide how to treat an actor who interacts inappropriately with an avatar while unaware that the avatar is controlled by a child. 
Although this issue cannot be satisfactorily explored in this article, legislators and virtual developers must work together to actively manage this risk.

\section{B Methods of Criminalisation to Facilitate these Principles}

\section{Amendment to the Crimes Act 1961 to expand the definition of indecent assault in s 135 to include virtual indecent assault}

In light of the above principles, an amendment to s 135 would be insufficient to manage the immense complexities that will emerge in criminalising virtual worlds. The need for an adequate definition and the adjustment of legal tests could not be achieved. This would be too narrow a path towards addressing the harm. Furthermore, this only approaches the issue of virtual indecent assault. Action that is taken should aim to build a foundation from which other virtual issues can also be approached. It is not an attractive option to allow the courts to expand the interpretation of current legislation to include virtual acts. Reading in virtual indecent assault into s 135 of the Crimes Act would be beyond the scope of permissible judicial interpretation. I do not suggest that real and virtual assaults should be treated synonymously. Nevertheless, as a supplementary measure it would be beneficial to educate judges on the effects of virtual reality so that they are prepared for future issues that arise from the virtual realm.

\section{Amendment to the Crimes Act to include a section for virtual offences}

The most comprehensive and perhaps radical approach would be to amend the Crimes Act to include a section on virtual crimes. This would allow for a suitable definition to be established, for adequate legal tests to be created and would make a strong statement condemning virtual acts that cause harm. It would also convey to platform developers that action needs to be taken to facilitate the prevention of harm in their virtual environments. Technology-neutral language could be sufficiently adopted. The Crimes Act may not, however, be completely conducive to the flexibility required for virtual technology. Any drafting of legislation would be hampered by its inability to sufficiently prepare for the future of the technology. This issue could be mitigated by the creation of regulations to run alongside the legislation. This would allow the law to respond to new developments in an efficient manner. Nevertheless, the creation of new legislation to be incorporated into the Crimes Act would be a long and arduous process. I do not think virtual technology is at the stage where this is necessary. Even when it does reach the impact threshold, there will be other ways to prevent harm in the short term. This process may be a long term possibility, but should not be considered the next step in dealing with this issue. Any comprehensive legislative scheme should be developed through stepping stones that can respond to developments in the technology. It is necessary to identify a less extreme step that would still achieve the principles and limit the harm that is already occurring. 


\section{Amend the Harmful Digital Communications Act 2015 to encapsulate communication through immersive virtual environments}

A more practical, yet effective, solution would be to amend the Harmful Digital Communications Act 2015 to include virtual indecent assault. The purpose of the Act is to deter, prevent and mitigate harm caused to individuals by digital communications, and to provide victims of harmful digital communications with a quick and efficient means of redress. ${ }^{65}$ The Act defines harm as serious emotional distress. ${ }^{66}$ Digital communication is defined as any form of electronic communication and includes any text message, writing, photograph, picture, recording or other matter that is communicated electronically. ${ }^{67}$ This definition is suitably broad to include virtual interactions. Section 6 of the Act lists 10 communication principles that, if broken, may allow the court to make an order listed in s 19 . The Act also regulates the liability of the online server host. ${ }^{68}$ Although it is clear that the Act would have to be heavily amended to encompass virtual reality, the framework is congruent with the principles I have outlined. The communication principles, if expanded upon, would provide a flexible way of managing the complexities of virtual reality. This principled form of legislation is suitable for the pre-impact threshold technology as the communication principles would not need to be as specifically constructed as any provision in the Crimes Act. The regulation on server hosts could be adapted and reapplied to virtual platform hosts. The empowerment provisions including the orders the court can make under the Act would also have to be changed in order to apply to virtual environments. Most importantly, however, the serious emotional harm caused by online content that the Act aims to prevent resembles the harm of virtual indecent assault.

If it was decided that legislators wanted to limit the Harmful Digital Communications Act to its current scope, then a similar piece of legislation could be created specifically for virtual reality. The use of communication principles, the rules concerning liability of server hosts and the creation of particular court orders could be replicated in a virtual context. This would prevent the Act becoming cluttered from attempting to manage too many forms of digital technology. It would also be more effective in satisfactorily defining virtual technology and maintaining flexibility. Although this option is not perfect, it is arguably the most appropriate means of achieving the principles I have established. These principles and the discussion of their implementation should be used as a basis for further research and discussion.

65 Harmful Digital Communications Act 2015, s 3.

66 Section 4.

67 Section 4.

68 Section 23. 


\section{The potential of two-step prohibition}

Two-step prohibition is a potential form of criminalisation that may be developed as a part of the legislative instruments discussed. Two-step prohibition involves the issuance of civil prohibitory orders against persons who have been found engaged in, or who are expected to engage in, undesirable conduct. A breach of that order then becomes a criminal offence. ${ }^{69}$ The content of the civil order can vary, but may require the actor to cease further conduct of the same kind or prevent the actor from entering an environment where they are likely to commit this conduct. ${ }^{70}$ Hence, the possibility of criminal sanctions only arises in respect of future conduct, not the conduct that gave rise to the civil order. ${ }^{71}$ The effectiveness of two-step prohibition is the subject of debate. Simester and von Hirsch label it a "radical and problematic device". ${ }^{72}$ It is worth considering in the context of virtual reality, however, due to the issues it seeks to resolve. Two-step prohibition is primarily centred on offensive conduct that may be an insufficient wrong in isolation, but sufficient if committed repeatedly. This would therefore be a softer mode of intervention by the criminal law than I have suggested is necessary. The flexible nature of the civil order within two-step prohibition would, however, help mitigate the complications of virtual reality. In this context, the order at the first stage could involve a banning from the virtual platform. Then, if that order was breached, criminal punishment would follow.

The appropriateness of a two-step prohibition for indecent or offensive virtual conduct will require a more in-depth analysis. Simester and von Hirsch are critical of the quasi-judicial option as it bypasses certain safeguards that the criminal law imposes to protect individual freedoms. ${ }^{73}$ In order to prevent users from being undeservedly subject to such an order, platform owners would have to develop comprehensive methods of regulating virtual environments. Furthermore, removing criminal safeguards may expose users to condemnation by the criminal law solely because they breached the first order by logging into a virtual reality server. This may neglect the question of whether the act was in itself wrongful. It is also arguable at the other end of the spectrum that a civil order does not treat a virtual indecent assault seriously enough in light of the harm that may have occurred. Two-step prohibition would have to be carefully applied to avoid missing the point of criminal intervention. Amidst the obstacles that two-step prohibition must overcome, it is an option that could be cautiously investigated further.

69 Simester and von Hirsch, above n 27, at 213.

70 At 213.

71 At 216.

72 At 215.

73 At 218 . 


\section{CONCLUSION}

Virtual worlds must now be regarded as an extension of reality rather than a place of fantasy. The technology has reached a level of sophistication where the immersive experiences of users have proven to have extra-virtual effects. Through a case study of virtual indecent assault, I have discussed why the law should no longer be hesitant to take bold steps into the realm of virtual reality. The first step the law must take is to acknowledge that real harm can result from virtual acts. The next steps are uncertain due to the complexity of the rapidly-developing technology. The principles I have established aim to minimise this uncertainty and facilitate the criminal law's response. At this early stage, the principled approach will be most valuable where it remains loyal to the goal of preventing harm. On the basis of these principles, the possible amendment or replication of the Harmful Digital Communications Act may be one of the best ways to prevent harm arising from virtual indecent assault. This would be just a small step into a much bigger world of law and virtual reality. Yet, with an ever-expanding technology that holds so much potential, small steps will be the smartest way forward. 